\title{
Region of Treatment in Radiotherapy and Second Malignancies in Breast Cancer Patients
}

\author{
Wei Zhang $^{1 *}$, Aldo Becciolini ${ }^{2}$, Annibale Biggeri ${ }^{3,4}$, Paolo Pacini ${ }^{5}$, Colin R. Muirhead ${ }^{6}$ \\ ${ }^{1}$ Epidemiology Department, Centre for Radiation, Chemical and Environmental Hazards, Health Protection Agency, Didcot, UK; \\ ${ }^{2}$ Department of Clinical Physiopathology, University of Florence, Florence, Italy; ${ }^{3}$ Department of Statistics “G. Parenti”, University \\ of Florence, Florence, Italy; ${ }^{4}$ Biostatistics Unit, ISPO Cancer Prevention and Research Institute, Florence, Italy; ${ }^{5}$ Radiotherapy Unit, \\ General Hospital, Firenze, Italy; ${ }^{6}$ Institute of Health \& Society, University of Newcastle, Newcastle, UK. \\ Email: *wei.zhang@hpa.org.uk
}

Received July 19 ${ }^{\text {th }}, 2012$; revised August 21 ${ }^{\text {st }}, 2012$; accepted August 31 ${ }^{\text {st }}, 2012$

\begin{abstract}
A cohort study was conducted based on clinical records for 5248 women treated for breast cancer in Florence (Italy), with continuous follow up from 1965 to 1994. The subjects were categorised into groups such as no radiation treatment; breast dose only; and radiation doses in one, two, three or four of the following fields: namely internal mammary chain, supraclavicular nodes, axillary lymph nodes and chest wall. The Cox proportional hazards model for ungrouped survival data was used to estimate the relative risk for second cancer after radiotherapy delivered to different regions. The relative risk for all second cancers combined was statistically significantly raised if the internal mammary chain and supraclavicular nodes were irradiated. However, we found that the relative risk of the second malignancies could be reduced if all the locoregional lymph nodes (the internal mammary chain, supraclacicular nodes, axillary nodes) and chest wall are irradiated at the same time. If this finding can be verified by other large cohort studies or randomized clinical trials, it may have implications in clinical practice when deciding upon the targeted areas for radiotherapy; partial radiation treatment of the locoregional lymph nodes could raise the risk of second malignancies and should ideally be avoided.
\end{abstract}

Keywords: Second Cancer; Radiotherapy; Breast Cancer

\section{Introduction}

Many patients are diagnosed with breast cancer each year and are often treated with surgery followed by adjuvant radiation therapy [1]. With advances in early diagnosis and treatment, breast cancer is becoming an increasingly survivable disease resulting in a large population of long-term survivors. Recent trials have shown an overall survival benefit in favour of adjuvant radiotherapy for breast cancer [2-4]. Nevertheless, there is clear evidence for the association between radiation exposure and cancer, especially from epidemiological studies of survivors of the atomic bombings in Japan [5-6], as well as from various studies of medically-exposed groups [7]. In particular, irradiation of surrounding tissues during breast radiotherapy can cause second malignancies to develop within these tissues [8-9]. The second malignancy refers to a new primary cancer in a person who has survived an earlier cancer. The probability of a radiation induced second malignancy after radiotherapy is a topic that has been widely discussed [9-15]. While the benefit of radio-

"Corresponding author. therapy should outweigh the risks of developing subsequent cancers, it is important to evaluate the long-term consequences of breast cancer treatment.

Our study involved the analysis of clinical records for female breast cancer patients treated at the University of Florence (Italy) with radiotherapy and/or chemotherapy and/or hormonal therapy from 1965 to 1994 and who were subsequently followed-up [16]. Previous analysis of this cohort [17] compared the incidence of second primary cancers in a group of patients treated with radiation therapy for breast cancer to breast cancer patients not treated in this way. In that analysis, an increased relative risk of all second cancers combined following radiotherapy was found. The increased relative risk appeared five or more years after radiotherapy and appeared to be highest among women treated after the menopause. Increased relative risks were observed specifically for leukaemia and other solid cancers that exclude leukaemia and contralateral breast cancer. For contralateral breast cancer, no raised relative risk was observed during the period more than 5 years after radiotherapy.

Recent randomized trials [18] have demonstrated that 
locoregional nodal irradiation after mastectomy reduces locoregional recurrence and improves overall survival at 5 years after radiation therapy in women with node positive breast cancer. However, Obedian et al. [19] reported that the region of radiation treatment may affect the risk of the second cancer and suggested that this risk might be higher when the internal mammary nodes were irradiated. In our cohort, 26\% of those patients given radiotherapy had the mammary chain and supraclavicular nodes or chest wall irradiated. This provides an opportunity to examine further the relationship between the region of treatment and second cancers. In this paper, we evaluate the effect that the region of treatment in radiotherapy may have had on the subsequent risk of second malignancies among patients treated in Florence, based on categorising the patients into the following groups such as no radiation treatment, breast dose only, or radiation dose in one, two, three or four of the following fields: namely, internal mammary chain, supraclavicular nodes, axillary lymph nodes and chest wall.

\section{Materials and Methods}

Data were collected on 5248 patients with breast cancer who were submitted to radiotherapy, chemotherapy, hormonal therapy or no additional therapy at the University of Florence from June 1965 to December 1994 [17]. All of the patients had received surgery for breast cancer.

A treatment schedule of 2 Gy/day, 5 days/week, for a total dose up to $60 \mathrm{~Gy}$ was used. However, the regions treated with radiation differed from patient to patient. The exposed volume for a large number of patients was the breast only, while other patients had also other regions irradiated, such as internal mammary chain, supraclavicular nodes, axillary lymph nodes and chest wall.

Details of the method of follow-up and collection of data on second malignancies have been presented previously [17]. The end of follow-up for the subjects was chosen to be the earliest of: date of second cancer incidence, date of loss to follow-up, date of death and 31 December 1994. The follow-up time among surviving patients ranged from a minimum of 1 year to a maximum of 30 years, with a mean of 8 years. The overall average age at treatment was 54.7 years. The researchers carrying out the study had no identifiable details of patients forwarded to them and therefore ethical approval was not required under Italian laws when the project was initiated in 1996.

The Cox proportional hazards model for ungrouped survival data [20] was used to estimate the relative risk of second cancers after radiotherapy treatment and to evaluate how the risk varied according to other factors. Parameter estimation and significance testing were carried out using the Epicure software [21]. Since some patients also received chemotherapy and/or hormonal therapy, the relative risks of second cancers due to radiotherapy were reported both unadjusted and adjusted for chemotherapy and hormonal therapy to check if there were any confounding effects from these therapies. The analyses are stratified by age-at-treatment and age at outcome categories.

As well as all second cancers combined, leukaemia, contralateral breast cancer (i.e. cancer in the opposite breast to that in which cancer had previously been diagnosed) and all other cancers combined were considered. For leukaemia, the follow up period was chosen to be two years or more following treatment, in view of the evidence from other studies showing a short latency period for radiation-induced leukaemia [7]. For other cancers and for all second cancers combined, the followup period was chosen to be five years, in line with the pattern reported by Zhang et al. [17].

\section{Results}

As shown in Table 1, among the 5248 patients in the cohort, 261 patients (5\%) developed contralateral breast cancer, 8 patients $(0.15 \%)$ developed leukaemia and a total of 118 patients (2.25\%) developed other types of second cancers during the period of follow-up. The details of other second cancer types were presented previously by Zhang et al. [17]. The median time to development of a second malignancy was 3 years for contralateral breast cancer, 4.5 years for leukaemia and 4.4 years for other cancers combined.

Table 2 summarises the number of subjects based on the region of radiation treatment. Among the 3080 subjects who had a follow-up of 5 or more years, 1813 subjects had no radiation treatment and 804 subjects received breast dose only. 14 subjects were irradiated in only one of the four following fields: internal mammary chain, supraclavicular nodes, axillary lymph nodes and chest wall, 138 subjects were irradiated in only two of the above fields (87\% were internal mammary chain and supraclavicular nodes), 190 subjects received doses in three of the above fields (97\% were internal mammary chain, supraclavicular nodes and axillary nodes) and 114 subjects received doses in all four fields. A very small number of subjects received breast doses in addition to doses in "other fields", as indicated by + in Table 2 and

Table 1. Sites of second malignancies.

\begin{tabular}{ccc}
\hline Second cancer type & $\begin{array}{c}\text { Numbers of total } \\
\text { second cancer patients }\end{array}$ & $\begin{array}{c}\text { Numbers of second } \\
\text { cancer patients with } \\
\text { radiotherapy }\end{array}$ \\
\hline $\begin{array}{c}\text { Contralateral breast } \\
\text { cancer }\end{array}$ & 261 & 103 \\
Leukaemia & 8 & 7 \\
$\begin{array}{c}\text { Other type of } \\
\text { cancers combined }\end{array}$ & 118 & 54 \\
\hline
\end{tabular}


they are grouped together with patients who only received doses to "other fields" in the analyses. Seven subjects had radiation treatment but without information on the field of treatment, therefore they are included in the any radiation treatment group but are excluded in the field-specific treatment groups in the analyses.

Table 3 shows the relative risks of all second cancer combined amongst patients given radiotherapy according to the region of radiation treatment, based on a followup of 5 or more years and both unadjusted and adjusted for chemotherapy and hormonal therapy. The reference category consists of unirradiated patients. The relative risk was below one for radiation treatment of the breast only and greater than one for patients who received radiation dose in one, two or three of the other fields. In particular, the relative risk was statistically significantly raised for patients who received radiation dose in two fields, which-among $87 \%$ of the patients-were the internal mammary chain and supraclavicular nodes. However, the relative risk dropped below one for subjects irradiated in all four fields (internal mammary chain, supraclavicular nodes, axillary nodes and chest wall). After adjustment for chemotherapy and hormonal therapy, there was strong evidence of differences in the relative risk between the radiation treatment groups $(\mathrm{p}=0.002)$.

The relative risks for some specific types of second cancer have been studied previously [17]. We further analysed the relative risk of leukaemia, contralateral breast cancer and other cancers respectively, according to the region of radiation treatment. Table $\mathbf{4}$ shows the relative risks for leukaemia amongst patients given radiotherapy according to the region of radiation treatment based on a follow-up of 2 or more years. Although the numbers of leukaemia cases were small, the relative risks were statistically significantly raised for patients having either one or three other fields irradiated, based on 1 and 2 cases in the corresponding irradiated groups. In contrast, the relative risks appeared to be smaller amongst patients who received a breast dose only or who received doses in either two or all four fields other than the breast, compared to other the irradiated groups. The differences in relative risk between the radiation treatment groups were statistically significant ( $p=0.04$, after adjusting for chemotherapy and hormonal therapy).

Table 5 shows the relative risk of contralateral breast cancer amongst patients given radiotherapy according to the region of radiation treatment based on a follow-up of 5 or more years. The relative risks were below one for patients who received a breast dose only, or who had either three or all four of the non-breast fields irradiated. In particularly, the relative risk was statistically significantly less than one for patients with radiation exposure only of the breast. The relative risks for patients who received radiation doses to either one or two of the
Table 2. Region of treatment and corresponding number of subjects, based on the follow-up of 5 or more years. The numbers of subjects who received breast dose in addition to other fields are represented as + numbers.

\begin{tabular}{|c|c|c|}
\hline Fields exposed & Number of subjects & Percentage (\%) \\
\hline None & 1813 & 58.86 \\
\hline Breast only & 804 & 26.10 \\
\hline \multicolumn{3}{|l|}{ One other field exposed } \\
\hline Internal mammary nodes & $2+1$ & \\
\hline Supraclavicular nodes & $4+1$ & \\
\hline Chest wall & 5 & \\
\hline Axillary nodes & 1 & \\
\hline subtotal & 14 & 0.45 \\
\hline \multicolumn{3}{|l|}{ Two other fields exposed } \\
\hline $\begin{array}{l}\text { Internal mammary nodes } \\
\text { and chest wall }\end{array}$ & 1 & \\
\hline $\begin{array}{l}\text { Internal mammary nodes } \\
\text { and supraclavicular nodes }\end{array}$ & $118+2$ & \\
\hline $\begin{array}{l}\text { Supraclavicular nodes and } \\
\text { axillary nodes }\end{array}$ & $12+1$ & \\
\hline $\begin{array}{l}\text { Supraclavicular nodes and } \\
\text { chest wall }\end{array}$ & 4 & \\
\hline Subtotal & 138 & 4.48 \\
\hline \multicolumn{3}{|l|}{ Three other fields exposed } \\
\hline $\begin{array}{l}\text { Internal mammary nodes, } \\
\text { supraclavicular nodes and } \\
\text { axillary nodes }\end{array}$ & $178+6$ & \\
\hline $\begin{array}{l}\text { Internal mammary nodes, } \\
\text { supraclavicular nodes and } \\
\text { chest wall }\end{array}$ & 5 & \\
\hline $\begin{array}{l}\text { Supraclavicular nodes, chest } \\
\text { wall and axillary nodes }\end{array}$ & 1 & \\
\hline Subtotal & 190 & 6.17 \\
\hline \multicolumn{3}{|l|}{ Four other fields exposed } \\
\hline $\begin{array}{l}\text { Internal mammary nodes, } \\
\text { supraclavicular nodes, chest } \\
\text { wall and axillary nodes }\end{array}$ & $111+3$ & \\
\hline Subtotal & 114 & 3.70 \\
\hline Fields unknown & 7 & 0.23 \\
\hline Total & 3080 & 100 \\
\hline
\end{tabular}


Table 3. Relative risk of all second cancers combined among patients given radiation therapy, by region of radiation treatment and based on a follow-up of 5 or more years.

\begin{tabular}{|c|c|c|c|}
\hline Region of radiation treatment & $\begin{array}{l}\text { RR unadjusted for chemotherapy and } \\
\text { hormonal therapy (95\% CI) }\end{array}$ & $\begin{array}{l}\text { RR adjusted for chemotherapy and } \\
\text { hormonal therapy (95\% CI) }\end{array}$ & Cases/women \\
\hline None & 1 & 1 & $94 / 1813(5.2 \%)$ \\
\hline Any radiation treatment & $1.22(0.88,1.69)$ & $1.14(0.82,1.58)$ & 73/1267 (5.8\%) \\
\hline \multicolumn{4}{|l|}{ Subgroups } \\
\hline Breast only & $0.79(0.49,1.28)$ & $0.70(0.43,1.14)$ & $24 / 804(3.0 \%)$ \\
\hline One other field ${ }^{* *}$ & $2.95(0.71,12.14)$ & $3.13(0.76,12.91)$ & 2/14 (14.3\%) \\
\hline Two other fields $^{* *}$ & $1.99(1.15,3.43)^{*}$ & $2.05(1.19,3.56)^{*}$ & 16/138 (11.6\%) \\
\hline Three other fields ${ }^{* *}$ & $1.59(0.93,2.74)$ & $1.50(0.87,2.56)$ & 18/190 (9.5\%) \\
\hline Four other fields ${ }^{* *}$ & $0.83(0.36,1.94)$ & $0.76(0.33,1.77)$ & 6/114 (5.3\%) \\
\hline $\begin{array}{l}\text { Test for heterogeneity in RR between } \\
\text { radiation treatment subgroups }\end{array}$ & $p=0.054$ & $p=0.002$ & \\
\hline
\end{tabular}

Table 4. Relative risk of leukaemia among patients given radiation therapy, by region of radiation treatment and based on a follow-up of 2 or more years.

\begin{tabular}{|c|c|c|c|}
\hline Region of radiation treatment & $\begin{array}{l}\text { RR unadjusted for chemotherapy } \\
\text { and hormonal therapy ( } 95 \% \mathrm{CI})\end{array}$ & $\begin{array}{l}\text { RR adjusted for chemotherapy and } \\
\text { hormonal therapy }(95 \% \mathrm{CI})\end{array}$ & Cases/women \\
\hline None & 1 & 1 & $1 / 2377(0.04 \%)$ \\
\hline Any radiation treatment & $8.13(0.96,69.10)$ & $6.67(0.76,58.00)$ & 7/2339 (0.3\%) \\
\hline \multicolumn{4}{|l|}{ Subgroups } \\
\hline Breast only & $4.17(0.41,42.62)$ & $3.27(0.32,33.72)$ & 3/1691 (0.18\%) \\
\hline One other field ${ }^{* *}$ & $72.09(4.05,1284)^{*}$ & $88.61(4.54,1728)^{*}$ & $1 / 25(4 \%)$ \\
\hline Two other fields ${ }^{* *}$ & NC & NC & 0/187 (0\%) \\
\hline Three other fields ${ }^{* *}$ & $24.71(3.44,278.90)^{*}$ & $18.85(1.69,210.80)^{*}$ & 2/252 (0.8\%) \\
\hline Four other fields ${ }^{* *}$ & $15.13(0.92,247.60)$ & $9.58(0.57,161.30)$ & $1 / 176(0.6 \%)$ \\
\hline $\begin{array}{l}\text { Test for heterogeneity in RR between radiation } \\
\text { treatment subgroups }\end{array}$ & $\mathrm{p}=0.03$ & $p=0.04$ & \\
\hline
\end{tabular}

${ }^{*} \mathrm{p}<0.05,{ }^{* *}$ defined in Table 2. NC: not calculated due to zero cases.

Table 5. Relative risk of contralateral breast cancer among patients given radiation therapy, by region of radiation treatment and based on a follow-up of 5 or more years.

\begin{tabular}{|c|c|c|c|}
\hline Region of radiation treatment & $\begin{array}{l}\text { RR unadjusted for chemotherapy } \\
\text { and hormonal therapy (95\% CI) }\end{array}$ & $\begin{array}{l}\text { RR adjusted for chemotherapy and } \\
\text { hormonal therapy ( } 95 \% \text { CI) }\end{array}$ & Cases/women \\
\hline None & 1 & 1 & 67/1813 (3.7\%) \\
\hline Any radiation treatment & $0.87(0.58,1.32)$ & $0.82(0.54,1.24)$ & $41 / 1267(3.2 \%)$ \\
\hline \multicolumn{4}{|l|}{ Subgroups } \\
\hline Breast only & $0.57(0.31,1.08)$ & $0.52(0.27,0.98)^{*}$ & 13/804 (1.6\%) \\
\hline One other field ${ }^{* *}$ & $2.20(0.30,16.22)$ & $2.33(0.32,17.13)$ & $1 / 14(7.1 \%)$ \\
\hline Two other fields** & $1.25(0.59,2.66)$ & $1.28(0.60,2.73)$ & 8/138 (5.8\%) \\
\hline Three other fields ${ }^{* *}$ & $0.94(0.43,2.04)$ & $0.89(0.41,1.94)$ & $8 / 190(4.2 \%)$ \\
\hline Four other fields $^{* *}$ & $0.68(0.24,1.94)$ & $0.63(0.23,1.80)$ & 4/114 (3.5\%) \\
\hline $\begin{array}{l}\text { Test for heterogeneity in RR between radiation } \\
\text { treatment subgroups }\end{array}$ & $p=0.43$ & $p=0.06$ & \\
\hline
\end{tabular}

${ }^{*} \mathrm{p}<0.05,{ }^{* *}$ defined in Table 2 . 
fields were greater than 1 , but were based on small numbers of cases and were not statistically significantly raised. The differences in relative risk between the radiation treatment groups were close to being statistically significant $(\mathrm{p}=0.06)$, after adjusting for chemotherapy and hormonal therapy).

Table 6 shows the relative risk of all second cancers other than leukaemia and contralateral breast cancer among patients given radiotherapy according to the region of radiation treatment based on a follow-up of 5 or more years. The relative risk was close to 1 for patients who received a breast dose only or who were irradiated in all four of the other fields. There were no cases amongst the 14 patients who received a radiation dose in only one of the fields. However, for patients who received radiation doses in two or three of the fields, statistically significantly raised relative risks were observed. The test for heterogeneity in the relative risk between radiation treatment groups was borderline statistically significant $(\mathrm{p}=0.05$, after adjusting for chemotherapy and hormonal therapy).

\section{Discussion}

In this study, we have used a clinical records-based cohort to analyse the effects of region of treatment in radiotherapy for breast cancer on the incidence of subsequent second cancers. All patients in this cohort received surgery for breast cancer. An advantage of restricting the cohort to women treated for breast cancer is to minimize any possible systematic difference between the study groups. Such an approach has been used in other epidemiological studies of a similar nature, as reported by Roychoudhuri et al. [13].

Our cohort contains $26 \%$ of radiotherapy patients who had the mammary chain and supraclavicular nodes or chest wall irradiated. This provided an opportunity to examine the relationship between the region of treatment and second cancers. Based on a follow-up of five or more years, the relative risk of all second cancers was highest for patients who received radiation to one or two fields apart from the breast; in particular, the risk was statistically significantly raised for patients irradiated in two fields. Amongst them, $87 \%$ received radiation exposure in internal mammary chain and supraclavicular nodes. This result is consistent with the finding of Obedian et al. [19], which suggested a raised risk of second cancer when the internal mammary chain was exposed. Furthermore, we also found that the relative risk started to decrease when axillary lymph nodes was also irradiated and was less than one (although not significantly so) for those subjects irradiated in all four fields. Thus, in order to reduce the risk of second cancer following radiotherapy for breast cancer, it might be important when irradiating the internal mammary chain and supraclavicular nodes to also irradiate the chest wall and axillary lymph nodes.

An increased risk of leukaemia can start to arise two to five years after exposure to radiation [22] and raised leukaemia risks have been reported in previous epidemiological studies of breast cancer patients treated with radiation [23]. This raised risk might be associated with regional radiation therapy that includes an internal mammary node field, which may expose the thoracic spine to a relatively high radiation dose [9]. In our previous

Table 6. Relative risk of second cancers other than leukaemia and contralateral breast cancer among patients given radiation therapy, by region of radiation treatment and based on a follow-up of 5 or more years.

\begin{tabular}{|c|c|c|c|}
\hline Region of radiation treatment & $\begin{array}{l}\text { RR unadjusted for chemotherapy and } \\
\text { hormonal therapy } \\
\text { (95\% CI) }\end{array}$ & $\begin{array}{l}\text { RR adjusted for chemotherapy and } \\
\text { hormonal therapy } \\
(95 \% \mathrm{CI})\end{array}$ & Cases/women \\
\hline None & 1 & 1 & 29/1813 (1.6\%) \\
\hline Any radiation treatment & $1.84(1.06,3.16)$ & $1.70(0.98,2.94)$ & 29/1267 (2.3\%) \\
\hline \multicolumn{4}{|l|}{ Subgroups } \\
\hline Breast only & $1.34(0.63,2.82)$ & $1.17(0.55,2.50)$ & $11 / 804(1.4 \%)$ \\
\hline One other field ${ }^{* *}$ & NC & NC & 0/14 (0.0\%) \\
\hline Two other fields** & $3.65(1.63,8.21)^{*}$ & $3.88(1.72,8.77)^{*}$ & 8/138 (5.8\%) \\
\hline Three other fields ${ }^{* *}$ & $2.36(1.02,5.48)^{*}$ & $2.19(0.94,5.08)$ & $8 / 190(4.2 \%)$ \\
\hline Four other fields ${ }^{* *}$ & $1.08(0.25,4.65)$ & $0.98(0.23,4.20)$ & $2 / 114(1.8 \%)$ \\
\hline $\begin{array}{l}\text { Test for heterogeneity in RR between radiation } \\
\text { treatment subgroups }\end{array}$ & $\mathrm{p}=0.06$ & $\mathrm{p}=0.053$ & \\
\hline
\end{tabular}

${ }^{*} \mathrm{p}<0.05,{ }^{* *}$ defined in Table 2. NC: not calculated due to zero cases. 
analysis [17], there was suggestion of a raised incidence of leukaemia among radiotherapy patients in the period two or more years after radiotherapy. There were seven cases in the radiotherapy group compared with only one case in non-radiotherapy group, with a relative risk of 6.67 (95\% CI 0.76, 58.00) after adjustment for chemotherapy and hormonal therapy. The raised risk was not statistically significant, reflecting the small number of cases in this cohort. In the current analysis, the relative risk of leukaemia peaked when one of the fields other than the breast was irradiated, albeit based on only one case. The relative risk was lower if more fields were irradiated, or if only the breast was irradiated. There were no leukaemia cases among the subjects who was irradiated in two of the fields; this might be due to chance, since there was only a total of 7 cases in the irradiated groups.

Raised risks of breast cancer has been reported in various studies of women exposed to radiation; for example, Japanese atomic bomb survivors [5,6,24], female tuberculosis patients who received multiple fluoroscopies $[25,26]$, and female patients who received radiotherapy for various benign conditions [27]. Raised risks have also been seen specifically in women who had direct breast exposure prior to the age of 30 years [26-30]. However, the causes of contralateral breast cancer amongst breast cancer patients given radiotherapy are less obvious. In the Early Breast Cancer Trialists' Collaborative Group report which evaluated the effects of radiotherapy, a significantly increased risk of contralateral breast cancer was found [31]. However, in another large case-control study from Denmark, there was no significant raised risk of contralateral breast cancer among women who received radiotherapy [32]. A more recent large-scale study included 13,472 women also failed to show an increased risk of contralateral breast cancer for those received radiotherapy [33]. The WECARE study [34] also reported that no excess risk was observed in women who received radiotherapy at more than 40 years of age, but a relative risk of 3.0 (95\% CI: 1.1 - 8.1) was reported in women aged $<40$ years with follow up greater than 5 years. Further analysis of data from the WECARE study found a raised risk of contralateral breast cancer among nulliparous (but not parous) women who received radiotherapy [35]. In some studies, it was reported that the increased risks of contralateral breast cancer were most likely observed within the first year following diagnosis of the primary breast cancer [36], or associated with patients with more advanced stage disease [37-39]. This suggests metastatic disease in the opposite breast could be mistakenly classified as a new primary second breast cancer. Since some patients selected for post-mastectomy radiation have a poorer prognosis than other patients, there may well be bias in estimates of the risk of contra- lateral breast cancer that can be attributed to radiotherapy. In order to minimise any effect of metastatic disease in the opposite breast, our analyses excluded the first five years following treatment. In our previous analysis [17], no raised relative risk for contralateral breast cancer was observed during the period five or more years after exposure. This is in agreement with previous epidemiological studies [9,32,33,40]. However, our current analysis showed that the relative risk was significantly below one for patients who received radiation exposure of the affected breast only. In contrast, the relative risk for patients irradiated in one or more other fields was not statistically significantly different from one. However, it has to bear in mind that our findings are based on small numbers of cases and should be verified by a larger study of similar kind.

Other solid cancers have also been reported to link with radiotherapy following breast cancer $[10,41,42]$. In our previous analysis, the relative risk of all second cancers excluding leukaemia and contralateral breast cancer appeared to be increased five or more years after radiotherapy, particularly amongst those women treated at ages 50 - 64 years age-at-treatment group. This may indicate an association with menopausal status [17]. The current analysis showed that the relative risk of all second cancers excluding leukaemia and contralateral breast cancer was statistical significantly raised among patients who received radiation dose in two fields, even after adjustment for chemotherapy and hormonal therapy. The relative risk was lower if three fields were exposed and dropped to around one when all four fields were exposed. These results are similar to those for all second cancers combined.

The findings in this paper could have clinical implications if they can be verified by other large cohort studies or randomised clinical trials. In this cohort study, we have no information on how the decisions were made about nodal irradiation treatment, which limits our interpretation of the results. With a fairly small total number of second cancers in this cohort, the excess risk associated with radiotherapy was small over the period of follow-up. Nevertheless, since many of the women were still alive at the end of follow-up, the possibility of raised risks continuing several decades over radiotherapy cannot be ruled out and-based on other studies (e.g. Preston et al. [6])—would be expected.

\section{Conclusion}

This study indicated a raised risk of second malignancies associated with region of treatment in radiotherapy for breast cancer, particularly among women irradiated in the internal mammary chain and supraclavicular nodes. The relative risk was lower if the axillary nodes and 
chest wall were also irradiated. This may have implications in clinical practice when deciding upon the targeted areas for radiotherapy; partial radiation treatment of the locoregional lymph nodes could raise the risk of second malignancies and should ideally be avoided. The interpretation of patterns in risk for specific cancers, such as leukaemia and contralateral breast cancer, was complicated by the small numbers of cases. However, for both of these type of cancer, the similar risk patterns exist and the relative risk varied significantly between radiotherapy groups, after adjusting for chemotherapy and hormonally therapy.

\section{REFERENCES}

[1] V. L. Ernster, J. Barclay, K. Kerlikowske, D. Grady and I. C. Henderson, "Incidence of and Treatment for Ductal Carcinoma in Situ of the Breast," The Journal of the American Medical Association, Vol. 275, No. 12, 1996, pp. 913-918. doi:10.1001/jama.1996.03530360023033

[2] K. S. Hughes, L. A. Schnaper, D. Berry, C. Cirrincione, B. McCormick, B. Shank, J. Wheeler, B. A. Lorraine, L. A. Champion, T. J. Smith, B. L. Smith, C. Shapiro, H. B. Muss, E. Winer, C. Hudis, W. Wood, D. Sugarbaker, I. C. Henderson and L. Norton, "Lumpectomy Plus Tamoxifen with or without Irradiation in Women 70 Years of Age or Older with Early Breast Cancer," The New England Journal of Medicine, Vol. 351, 2004, pp. 971-977. doi:10.1056/NEJMoa040587

[3] V. Vinh-Hung, C. Verschraegen for the Breast Conserving Surgery Project, "Breast-Conserving Surgery with or without Radiotherapy: Pooled-Analysis for Risks of Ipsilateral Breast Tumour Recurrence and Mortality,” Journal of the National Cancer Institute, Vol. 96, No. 2, 2004, pp. 115-121. doi:10.1093/jnci/djh013

[4] V. Gebski, M. Lagleva, A. Keech, J. Simes and A. O. Langlands, "Survival Effects of Postmastectomy Adjuvant Radiation Therapy Using Biologically Equivalent Doses: A Clinical Perspective," Journal of the National Cancer Institute, Vol. 98, No. 14, 2006, pp. 26-38.

[5] C. E. Land, M. Tokunaga, K. Koyama, M. Soda, D. L. Preston, I. Nishimori and S. Tokuoka, "Incidence of Female Breast Cancer among Atomic Bomb Survivors, Hiroshima and Nagasaki, 1950-1990,” Radiation Research, Vol. 160, No. 6, 2003, pp. 707-717. doi:10.1667/RR3082

[6] D. L. Preston, Y. Shimizu, D. A. Pierce, A. Suyama and K. Mabuchi, "Studies of Mortality of Atomic Bomb Survivors. Report 13: Solid Cancer and Noncancer Disease Mortality: 1950-1997,” Radiation Research, Vol. 160, No. 4, 2003, pp. 381-407. doi:10.1667/RR3049

[7] United Nations Scientific Committee on the Effects of Atomic Radiation (UNSCEAR 2008), "2006 Report to the General Assembly with Scientific Annex,” United Nations, New York.

[8] E. B. Harvey and L. A. Brinton, "Second Cancer Following Cancer of the Breast in Connecticut, 1935-82," National Cancer Institute Monograph, Vol. 68, 1985, pp. 99-112.
[9] A. I. Neugut, M. D. Weinberg, H. Ahsan and J. Rescigno, "Carcinogenic Effects of Radiotherapy for Breast Cancer,” Oncology, Vol. 13, 9, 1999, pp. 1245-1256.

[10] L. M. Brown, B. E. Chen, R. M. Pfeiffer, C. Schairer, P. Hall, H. Storm, E. Pukkala, F. Langmark, M. Kaijser, M. Andersson, H. Joensuu, S. D. Fossa and L. B. Travis, "Risk of Second Non-Hematological Malignancies among 376,825 Breast Cancer Survivors," Breast Cancer Research and Treatment, Vol. 106, No. 3, 2007, pp. 439451. doi:10.1007/s10549-007-9509-8

[11] L. Mellemkjaer, S. Friis, J. H. Olsen, G. Scelo, K. Hemminki, E. Tracey, A. Andersen, D. H. Brewster, E. Pukkala, M. L. McBride, E. V. Kliewer, J. M. Tonita, C. Kee-Seng, V. Pompe-Kirn, C. Martos, J. G. Jonasson, P. Boffetta and P. Brennan, "Risk of Second Cancer among Women with Breast Cancer," International Journal of Cancer, Vol. 118, No. 9, 2006, pp. 2285-2292. doi:10.1002/ijc. 21651

[12] J. S. Raymond and C. J. Hogue, "Multiple Primary Tumours in Women following Breast Cancer, 1973-2000," British Journal of Cancer, Vol. 94, No. 11, 2006, pp. 1745-1750.

[13] R. Roychoudhuri, H. Evans, D. Robinson and H. Møller, "Radiation-Induced Malignancies following Radiotherapy for Breast Cancer,” British Journal of Cancer, Vol. 91, No. 5, 2004, pp. 868-872.

[14] S. Galper, R. Gelman, A. Recht, B. Silver, A. Kohli, J. S. Wong, T. Van Buren, E. H. Baldini and J. R. Harris, "Second Nonbreast Malignancies after Conservative Surgery and Radiation Therapy for Early-Stage Breast Cancer,” International Journal of Radiation Oncology, Biology and Physics, Vol. 52, No. 2, 2002, pp. 406-414. doi:10.1016/S0360-3016(01)02661-X

[15] B. Fowble, A. Hanlon, G. Freeman, N. Nicolaou and P. Anderson, "Second Cancer after Conservative Surgery and Radiation for Stages I-II Breast Cancer: Identifying a Subset of Women at Increased Risk," International Journal of Radiation Oncology, Biology and Physics, Vol. 51, No. 3, 2001, pp. 679-690.

[16] A. Becciolini, A. Biggeri, P. Pacini and M. Baccini, “Breast Cancer Cohort: Florence 1965-1994,” The Proceedings of the XV International Scientific Meeting of the International Epidemiological Association, Florence, 31 August-4 September 1999.

[17] W. Zhang, A. Becciolini, A. Biggeri, P. Pacini and C. R. Muirhead, "Second Malignancies in Breast Cancer Patients Following Radiotherapy: A Study in Florence, Italy,” Breast Cancer Research, Vol. 13, No. 2, 2011, p. R38. doi:10.1186/bcr2860

[18] T. J. Whelan, I. Olivotto, I. Ackerman, J. W. Chapman, B. Chua, A. Nabid, K. A. Vallis, J. R. White, P. Rousseau, A. Fortin, L. J. Pierce, L. Manchul, P. Craighead, M. C. Nolan, J. Bowen, D. R. McCready, K. I. Pritchard, M. N. Levine and W. Parulekar, "NCIC-CTG MA.20: An Intergroup Trial of Regional Nodal Irradiation in Early Breast Cancer,” Journal of Clinical Oncology, Vol. 29, No. 18, 2011, Abstract LBA1003.

[19] E. Obedian, D. B. Fischer and B. G. Haffty, "Second Malignancies after Treatment of Early-Stage Breast Can- 
cer: Lumpectomy and Radiation Therapy versus Mastectomy,” Journal of Clinical Oncology, Vol. 18, No. 12, 2000, pp. 2406-2412.

[20] N. E. Breslow and N. E. Day, "The Design and Analysis of Cohort Studies," In: Statistical Methods in Cancer Research, Vol. 2, International Agency for Research on Cancer, Lyon, 1987, pp. 120-178.

[21] D. L. Preston, J. H. Lubin, D. A. Pierce and M. E. McConney, "Epicure User Guide," Hirosoft International Corporation, Seattle, Washington, 1993.

[22] J. D. Boice, C. E. Land and D. L. Preston, "Ionizing Radiation,” In: D. Schottenfeld and J. F. Fraumeni, Eds., Cancer Epidemiology and Prevention, Oxford University Press, New York, 1996, pp. 319-341.

[23] R. E. Curtis, J. D. Boice, Jr., M. Stovall, L. Bernstein, R. S. Greenberg, J. T. Flannery, A. G. Schwartz, P. Weyer, W. C. Moloney and R. N. Hoover, "Risk of Leukemia after Chemotherapy and Radiation Treatment for Breast Cancer,” The New England Journal of Medicine, Vol. 326, 1992, pp. 1745-1751. doi:10.1056/NEJM199206253262605

[24] D. L. Preston, A. Mattsson, E. Holmberg, R. Shore, N. G. Hildreth and J. D. Boice, Jr., "Radiation Effects on Breast Cancer Risk: A Pooled Analysis of Eight Cohorts,” Radiation Research, Vol. 158, No. 2, 2002, pp. 220-235. doi:10.1667/0033-7587(2002)158[0220:REOBCR]2.0.C $\underline{\mathrm{O} ; 2}$

[25] M. P. Little and J. D. Boice Jr., “Comparison of Breast Cancer Incidence in the Massachusetts Tuberculosis Fluoroscopy Cohort and in the Japanese Atomic Bomb Survivors,” Radiation Research, Vol. 151, No. 2, 1999, pp. 218-224. doi:10.2307/3579773

[26] J. D. Boice Jr., D. Preston, F. G. Davis and R. R. Monson, "Frequent Chest $\mathrm{x}$-Ray Fluoroscopy and Breast Cancer Incidence among Tuberculosis Patients in Massachusetts,” Radiation Research, Vol. 125, No. 2, 1991, pp. 214-222. doi: $10.2307 / 3577890$

[27] R. E. Shore, L. H. Hemplemann, E. Kowaluk, P. S. Mansur, B. S. Pasternack, R. E. Albert and G. E. Haughie, "Breast Neoplasms in Women Treated with X-Rays for Acute Post-Partum Mastitis," Journal of the National Cancer Institute, Vol. 59, No. 3, 1977, pp. 813-822.

[28] D. H. McGregor, C. E. Land, K. Choi, S. Tokuka, P. I. Liu and T. Wakabayashi, "Breast Cancer Incidence among Atomic Bomb Survivors, Hiroshima and Nagasaki 19501969,” Journal of the National Cancer Institute, Vol. 59, No. 3, 1977, pp. 799-811.

[29] A. Tinger, T. H. Wasserman, E. E. Klein, E. A. Miller, T. Roberts, J. V. Piephoff and N. A. Kucik, "The Incidence of Breast Cancer following Mantle Field Radiation Therapy as a Function of Dose And Technique,” International Journal of Radiation Oncology, Biology and Physics, Vol. 37, No. 4, 1997, pp. 865-870. doi:10.1016/S0360-3016(97)00026-6

[30] S. L. Hancock, M. A. Tucker and R. T. Hoppe, "Breast Cancer after Treatment of Hodgkin's Disease,” Journal of the National Cancer Institute, Vol. 85, No. 1, 1993, pp. 25-31. doi:10.1093/jnci/85.1.25

[31] M. Clarke, R. Collins, S. Darby, C. Davies, P. Elphin- stone, V. Evans, J. Godwin, R. Gray, C. Hicks, S. James, E. MacKinnon, P. McGale, T. McHugh, R. Peto, C. Taylor and Y. Wang, "Effects of Radiotherapy and of Differences in the Extent of Surgery for Early Breast Cancer on Local Recurrence and 15 Year Survival: An Overview of the Randomised Trials," Lancet, Vol. 366, No. 9503, 2005, pp. 2087-2106.

[32] H. H. Storm, M. Andersson, J. D. Boice, M. Blettner, M. Stovall, H. T. Mouridsen, P. Dombernowsky, C. Rose, A. Jacobsen and M. Pedersen, "Adjuvant Radiotherapy and Risk of Contralateral Breast Cancer," Journal of the National Cancer Institute, Vol. 84, No. 16, 1992, pp. 12451250. doi:10.1093/jnci/84.16.1245

[33] Y. M. Kirova, L. Gambotti, Y. De Rycke, J. R. Vilcoq, B. Asselain and A. Fourquet, "Risk of Second Malignancies after Adjuvant Radiotherapy for Breast Cancer: A LargeScale, Single-Institution Review,” International Journal of Radiation Oncology, Biology and Physics, Vol. 68, No. 2, 2007, pp. 359-363. doi:10.1016/j.ijrobp.2006.12.011

[34] M. Stovall, S. A. Smith, B. M. Langholz, J. D. Boice, R. E. Shore, M. Andersson, T. A. Buchholz, M. Capanu, L. Bernstein, C. F. Lynch, K. E. Malone, H. Anton-Culver, R. W. Haile, B. S. Rosenstein, A. S. Reiner, D. C. Thomas, J. L. Bernstein and WECARE Study Collaborative Group, "Dose to the Contralateral Breast from Radiotherapy and Risk of Second Primary Breast Cancer in the WECARE Study," International Journal of Radiation Oncology, Biology and Physics, Vol. 72, No. 4, 2008, pp. 1021-1030. doi:10.1016/j.ijrobp.2008.02.040

[35] J. D. Brooks, J. D. Boice, M. Stovall, A. S. Reiner, L. Bernstein, E. M. John, C. F. Lynch, L. Mellemkjaer, J. A. Knight, D. C. Thomas, R. W. Haile, S. A. Smith, M. Capanu, J. L. Bernstein and R. E. Shore, "Reproductive Status at First Diagnosis Influences Risk of Radiation-Induced Second Primary Contralateral Breast Cancer in the WECARE Study," International Journal of Radiation Oncology, Biology and Physics, 2012, Epub 2012/ $04 / 10$.

[36] P. L. Horn, W. D. Thompson and S. M. Schwartz, "Factors Associated with the Risk of Second Primary Breast Cancer: An Analysis of Data from the Connecticut Tumor Registry,” Journal of Chronic Diseases, Vol. 40, No. 11, 1987, pp. 1003-1011. doi:10.1016/0021-9681(87)90114-7

[37] J. M. Kurtz, R. Amalric, H. Brandone, Y. Ayme and J. M. Spitalier, "Contralateral Breast Cancer and Other Second Malignancies in Patients Treated by Breast-Conserving Therapy with Radiation,” International Journal of Radiation Oncology, Biology and Physics, Vol. 15, No. 2, 1988, pp. 277-284. doi:10.1016/S0360-3016(98)90005-0

[38] Broet P, de la Rochefordiere A, Scholl SM, Fourquet A, Mosseri V, Durand JC, Pouillart P and Asselain B, "Contralateral Breast Cancer: Annual Incidence and Risk Parameters,” Journal of Clinical Oncology, Vol. 13, No. 7, 1995, pp. 1578-1583.

[39] B. F. Hankey, R. E. Curtis, M. D. Naughton, J. D. Boice, Jr. and JT Flannery, “A Retrospective Cohort Analysis of Second Breast Cancer Risk for Primary Breast Cancer Patients with an Assessment of the Effect of Radiation Therapy,” Journal of the National Cancer Institute, Vol. 70, No. 5, 1983, pp. 797-804. 
[40] J. D. Boice, E. B. Harvey, M. Blettner, M. Stovall and J. T. Flannery, "Cancer in the Contralateral Breast after Radiotherapy for Breast Cancer,” The New England Journal of Medicine, Vol. 326, No. 12, 1992, pp. 781-785. doi:10.1056/NEJM199203193261201

[41] E. L. Kaufman, J. S. Jacobson, D. L. Hershman, M. Desai and A. I. Neugut, "Effect of Breast Cancer Radiotherapy and Cigarette Smoking on Risk of Second Primary Lung
Cancer,” Journal of Clinical Oncology, Vol. 26, No. 3, 2008, pp. 392-398. doi:10.1200/JCO.2007.13.3033

[42] C. Rubino, A. Shamsaldin, M. G. Le, M. Labbé, J. M. Guinebretiere, J. Chavaudra and F. De Vathaire, "Radiation Dose and Risk of Soft Tissue and Bone Sarcoma after Breast Cancer Treatment,” Breast Cancer Research and Treatment, Vol. 89, No. 3, 2005, pp. 277-288. doi:10.1007/s10549-004-2472-8 